\title{
Limited health literacy increases the risk of orthorexia nervosa among urban schoolteachers
}

\author{
Gülay Yilmazel* and Serpil Bozdogan**
}

ABSTRACT

\begin{tabular}{|c|}
\hline $\begin{array}{l}\text { *Hitit University Faculty of Health } \\
\text { Science, Public Health Department, } \\
\text { Çorum/TURKEY } \\
\text { **Hitit University Health Science } \\
\text { Institution, Çorum, TURKEY }\end{array}$ \\
\hline $\begin{array}{l}\text { Corespondence: } \\
\text { Assoc. Prof. Dr. Gülay Yilmazel } \\
\text { Hitit University Faculty of Health } \\
\text { Sciences, } \\
\text { Public Health Department, Corum, } \\
\text { TURKEY } \\
\text { Mobile: +903642230730-31 } \\
\text { Email: gulcenarin@yahoo.com } \\
\text { ORCID ID: 0000-0002-2487-5464 }\end{array}$ \\
\hline $\begin{array}{l}\text { Date of first submission, June } 19,2020 \\
\text { Date of final revised submission, } \\
\text { October } 6,2020 \\
\text { Date of acceptance, October 12, } 2020\end{array}$ \\
\hline $\begin{array}{l}\text { This open access article is distributed } \\
\text { under a Creative Commons Attribution- } \\
\text { Non Commercial-Share Alike } 4.0 \\
\text { International License }\end{array}$ \\
\hline $\begin{array}{l}\text { Cite this article as: Yilmazel G, } \\
\text { Bozdogan S. Limited health literacy } \\
\text { increases the risk of orthorexia nervosa } \\
\text { among urban schoolteachers. Univ Med } \\
2020 ; 39: 162-70 \text {. doi: } 10.18051 / \\
\text { UnivMed.2020.v39.162-170 }\end{array}$ \\
\hline
\end{tabular}

*Hitit University Faculty of Health Science, Public Health Department

**Hitit University Health Science

\section{Corespondence:}

Assoc. Prof. Dr. Gülay Yilmazel Sciences,

Public Health Department, Corum, TURKEY

Mobile:+903642230730-31

Email : gulcenarin@yahoo.com

Date of first submission, June 19, 2020

Date of final revised submission,

October 6, 2020

This open access article is distributed under a Creative Commons AttributionNon Commercial-Share Alike 4.0 International License

Cite this article as: Yilmazel G, Bozdogan S. Limited health literacy among urban schoolteachers. Univ Med 2020;39:162-70. doi: 10.18051

\section{BACKGROUND}

Orthorexia nervosa (ON) describes a pathological obsession with proper nutrition that is characterized by a restrictive diet, ritualized patterns of eating, and rigid avoidance of foods believed to be unhealthy or impure. Limited health literacy may play a role in the onset and progression of orthorexia. The aim of this study was to determine the relationship between health literacy and $\mathrm{ON}$ among urban schoolteachers.

\section{METHODS}

This cross-sectional study was conducted in central Black Sea region of Turkey with 420 primary and secondary schoolteachers aged between 18 and 51 years. A questionnaire form including socio-demographic characteristics was used. The Orthorexia Nervosa Questionnaire (ORTO15) was used to assess orthorexia nervosa behavior and the Turkey Health Literacy Scale (TSOY-32) to assess health literacy. Simple binary and multiple binary logistic regression analyses were carried out to verify the associations between the variables.

\section{RESULTS}

Of the study group $46.4 \%$ were in the $40-49$ year age group, $53.8 \%$ were male, $78.6 \%$ had ON and $93.6 \%$ had limited health literacy. Nearly all of the orthorexics (96.4\%) had limited health literacy. Female gender, Instagram use and limited health literacy was significantly associated with ON. Limited health literacy increases the risk of ON 4.85 times among teachers $(\mathrm{aOR}=4.85 ; 95 \%$ C.I. $: 2.15-10.94 ; \mathrm{p}=0.000)$.

\section{CONCLUSION}

The current findings suggest that limited health literacy is the strongest risk factor for ON among urban schoolteachers. School health literacy and social media literacy programs can open a new window into revealing $\mathrm{ON}$.

Keywords : Urban, schoolteachers, psychological eating disorder, health literacy 


\section{INTRODUCTION}

Noncommunicable diseases are one of the most important health problems of the $21 \mathrm{st}$ century and responsible for 41 million of the 57 million deaths in 2016 at the global level. Unhealthy diet is one of the key risk factors for noncommunicable diseases. ${ }^{(1)}$ Unhealthy diet pattern has increased worldwide. ${ }^{(2)}$ The pattern of nutrition shows a shift towards foods containing high salt, fat and sugar. Rapidly growing obesity prevalence due to sedentary lifestyle leads to a dramatic increase in diabetes, cardiovascular diseases, hypertension, osteoarthritis, cancer and many other health problems. ${ }^{(3,4)}$ In developed societies, the main focus of the people is consciousness on healthy nutrition and selectivity towards the quality, quantity and type of food. Developing a fixed idea on the amount or type of food often causes an irregular dietary pattern and excessively results in psychological eating disorders. ${ }^{(5)}$ Dissatisfaction with one's body, distorted body image perception and obsession with thinness are central to clinically diagnosed eating disorders (ED) such as anorexia nervosa (AN), bulimia nervosa (BN), binge eating disorder (BED) and eating disorders not otherwise specified (EDNOS). ${ }^{(6)}$ These factors may also contribute to other non-clinical types of disorders including orthorexia nervosa $(\mathrm{ON}) \cdot{ }^{(7)}$ Orthorexia nervosa defines a pathological obsession for proper nutrition, characterized by a restrictive diet, ritualized eating pattern, and strict avoidance of unhealthy or supplemented foods. ${ }^{(8)}$ The mean prevalence of orthorexic symptoms is reported to be $6.9 \%{ }^{(9)}$ for the general population and $28.3 \%-74.5 \%$ for high risk professions (dietetics, medicine, nursing, physiotherapy, midwifery, optometry, physical education and sport sciences, sociology, and teaching). ${ }^{(7,10)}$

In Turkey, ON prevalence is high (approximately 50\%) among candidate doctors and nurses. ${ }^{(11,12)}$ To assess ON, the Orthorexia Nervosa Questionnaire (ORTO-15) ${ }^{(13)}$ is widely used, despite criticism regarding this research tool. ${ }^{(14)}$ A study suggested that the ORTO-15 questionnaire may not be able to distinguish pathological behaviors and is not clinically relevant. ${ }^{(15)}$ However, a recent review of the studies using ORTO-15 showed that Cronbach's alpha coefficients were ranging from 0.83 to 0.91 . $^{(16)}$ In the original version of ORTO-15, to distinguish the orthorexic tendency it is recommended to use the cut-off point below 40 (17), and some studies followed this recommendation. ${ }^{(18,19)}$ Nevertheless, there are also suggestions to lower the cut-off point to $35 .^{(18,20)}$

In recent years, the density and popularity of social media channels have been blamed for the increased incidence of eating disorders worldwide. ${ }^{(21-24)}$ Previous studies have revealed that individuals with adequate health literacy consume less sugar-sweetened drinks and fried foods, and better amounts of vegetables and fruits. ${ }^{(25,26)}$

Health literacy refers to the competencies related to accessing, understanding, appraising and applying health information in the domains of healthcare, disease prevention and health promotion, respectively. ${ }^{(27)}$ Since its importance is increasingly recognized, to date, various frameworks or scales are available for assessing and measuring health literacy based on different subjects, diseases, or theoretical foundations. ${ }^{(28-}$ 32) To measure health literacy in the general population, there are also different measurement tools such as the European Health Literacy survey (HLS-EU-Q47) $^{(33)}$ and Turkish Health Literacy Scales. ${ }^{(34)}$ However, no reliable, definitive, and comparable health literacy scale exists for the global population. In Turkey, about seven of every ten people has limited health literacy level ${ }^{(34,35)}$ and orthorexia nervosa prevalence reaches $75 \%$. $^{(36)}$

Risk factors or characteristics that were listed by professionals to be associated with $\mathrm{ON}$ were excessive exercise, ${ }^{(37)}$ anxiety, use of social media, thin ideal internalization, and harm avoidance and low self-directedness. ${ }^{(38)}$ However, risk factors that may be particularly relevant to ON could include problems with health literacy. ${ }^{(8)}$ 
Teachers are model people in creating healthy lifestyle behaviors and providing health education in schools. There has been no detailed investigation of orthorexia tendency and health literacy among teachers. The aim of this study was to determine the relationship between health literacy and orthorexia nervosa among urban schoolteachers.

\section{METHODS}

\section{Research design}

This cross-sectional study was conducted between October-December 2019 in Corum city located in central Black Sea region of Turkey.

\section{Study subjects}

The population consisted of 1914 teachers working in urban primary and secondary schools. Based on the prevalence of $\mathrm{ON}$ of $45 \%$ in our country ${ }^{(13)}$, the minimum sample size was calculated as 317 teachers. Participants were recruited from nine public schools (four primary and five secondary) covering the urban area. A total of eligible 442 teachers from primary and secondary schools were included to the study with the stratified sampling method. Participants with diagnosed diet-related diseases (diabetes mellitus type I and II, Crohn's disease, celiac disease, gastritis) were excluded (22 participants).

\section{Instruments}

Participants were visited at their schools and completed an informed consent form, then received a survey including sociodemographic information, the use of social media, ORTO-15 and Turkey Health Literacy SCALE-32 (TSOY32) questionnaire. The survey took 20-30 minutes to answer the questionnaire. Three visits were made for each participant who could not be reached.

The data was collected with a 64-item form. The first stage of the questionnaire form included the participants' socio-demographic characteristics (age, gender, institution, branch, chronic condition, health perception, weight satisfaction, height and weight to calculate BMI), and details about the use of social media.

\section{Social media details}

Participants were asked "Which social media channels do you use?" and could select multiple responses out of: Instagram, Facebook, Twitter, Pinterest, Google+, Youtube, Snapcheck and LinkedIn. In the second stage, in order to identify orthorexia tendency and to assess health literacy levels, respectively, the ORTO-15 scale and TSOY-32 scale were used.

\section{Orthorexia nervosa (ORTO-15) Scale}

The scale consists of 15 items and is written in 4-degree format; always (4), often (3), sometimes (2), never (1). Items 2, 5, 8 and 9 (items $3,4,6,7,10,11,12,14,15)$ scored on the scale are reversed. The answers which distinguish criteria for orthorexia, were given as "1", and those with a tendency to normal eating behavior were given as " 4 ". A minimum of 15 and a maximum of 60 points can be obtained from the scale. The cut-off point of the scale was considered to be 40 in predicting orthorexic behavior and tendency. Those with ORTO-15 scale score of $<40$ were considered to be orthorexic and those with a score of $\geq 40$ were evaluated as normal. ${ }^{(13)}$ An adaptation of the scale into Turkish was conducted in 2008. ${ }^{(39)} \mathrm{In}$ this study the original cut-off of $<40$ was considered as indicative of orthorexia nervosa.

\section{Turkey Health Literacy Scale (TSOY-32)}

The 32-item scale's validity and reliability were developed based on the HLS-EU Study Conceptual Framework (HLS-EU CONSORTIUM, 2012) in 2016. The scores obtained from the scale vary between 0 and 50 . According to the scores, the level of health literacy is classified into four categories: $0-25=$ inadequate health literacy; $>25-33=$ problematic health literacy; $>33-42=$ adequate health literacy; $>42-50=$ excellent health literacy. ${ }^{(34)}$ In this study, the inadequate/problematic health 
literacy of the participants was categorized as "limited" and adequate/excellent health literacy as "sufficient".

\section{Statistical analysis}

Data management and analysis were performed using SPSS software (version 17). Simple binary and multiple binary logistic regression analyses were used. To predict significant factors for orthorexia tendency, Odds ratio (OR) and $95 \%$ confidence interval (CI) were calculated. Significance levels were set at the 5\% level.

\section{Ethical clearance}

The research was planned in accordance with Helsinki Principles. Prior to undertaking the investigation ethical clearance was obtained from a local Non-Interventional Clinical Research Ethics Committee (2019-324).

\section{RESULTS}

Table 1 presents associations of several risk factors and orthorexia nervosa. In general, $78.6 \%$ teachers were orthorexics and the mean score of the ORTO-15 scale was $37.4(\mathrm{SD}=3.5)$. In the study group, $46.4 \%$ were between $40-49$ years of age, $53.8 \%$ were male, $78.6 \%$ were secondary schoolteachers and the mean age was $43.4 \pm 7.5$ years. A minority of participants $(21 \%)$ indicated that they had any chronic disease and almost three out of four teachers had good health perception. Just over half of those satisfied with body weight and had normal BMI. Orthorexia nervosa was significantly more common among

Table 1. Associations of several risk factors and orthorexia nervosa

\begin{tabular}{|c|c|c|c|c|c|}
\hline \multirow[b]{2}{*}{ Variables } & \multicolumn{2}{|c|}{ Orthorexia nervosa } & \multirow[b]{2}{*}{ OR } & \multirow[b]{2}{*}{ 95\% C.L. } & \multirow[b]{2}{*}{ p-value } \\
\hline & $\begin{array}{c}\text { Orthorexic } \\
(\mathrm{n}=\mathbf{3 3 0}, \mathbf{7 8 . 6 \%})\end{array}$ & $\begin{array}{c}\text { Normal } \\
(\mathrm{n}=90,21.4 \%)\end{array}$ & & & \\
\hline \multicolumn{6}{|l|}{ Age (yrs) } \\
\hline $25-39$ & $101(30.6)$ & $25(27.8)$ & 0.96 & $0.52-1.77$ & 0.873 \\
\hline $40-49$ & $152(46.1)$ & $43(47.8)$ & 0.79 & $0.37-1.70$ & \\
\hline $50-64$ & $77(23.3)$ & $22(24.4)$ & 1 & & \\
\hline \multicolumn{6}{|l|}{ Gender } \\
\hline Male & $169(51.2)$ & $57(63.3)$ & 0.97 & $0.37-0 . .98$ & 0.041 \\
\hline Female & $161(48.8)$ & $33(36.7)$ & 1 & & \\
\hline \multicolumn{6}{|l|}{ Institution } \\
\hline Primary school & $70(21.2)$ & $20(22.2)$ & 0.94 & $0.51-1.73$ & 0.836 \\
\hline Secondary school & $260(78.8)$ & $70(77.8)$ & 1 & & \\
\hline \multicolumn{6}{|l|}{ Chronic health problem } \\
\hline Yes & $68(18.2)$ & $20(31.2)$ & 1 & & \\
\hline No & $262(81.8)$ & $70(68.8)$ & 1.06 & $0.52-2.16$ & 0.698 \\
\hline \multicolumn{6}{|l|}{ Health perception } \\
\hline Good & $249(75.5)$ & $66(73.3)$ & 1 & & \\
\hline Moderate/poor & $81(24.5)$ & $24(26.7)$ & 1.15 & $0.60-2.20$ & 0.680 \\
\hline \multicolumn{6}{|l|}{ Weight satisfaction } \\
\hline Satisfied & $188(57.0)$ & $55(61.1)$ & 1 & & \\
\hline No satisfied & $142(43.0)$ & $35(38.9)$ & 0.83 & $0.45-1.53$ & 0.481 \\
\hline \multicolumn{6}{|l|}{ BMI } \\
\hline Normal & $177(53.6)$ & $45(50.0)$ & 1.39 & $0.24-2.15$ & 0.513 \\
\hline Overweight & $123(37.3)$ & $39(43.3)$ & 1.24 & $0.68-2.262$ & \\
\hline Obese & $30(9.1)$ & $6(6.7)$ & 1 & & \\
\hline \multicolumn{6}{|l|}{ Use of social media } \\
\hline Instagram & $196(59.4)$ & $39(43.3)$ & 1.73 & $1.03-2.89$ & 0.036 \\
\hline No Instagram user & $134(40.6)$ & $51(56.7)$ & 1 & & \\
\hline \multicolumn{6}{|l|}{ Health literacy } \\
\hline Limited & $318(96.4)$ & $75(83.3)$ & 4.95 & $2.16-11.37$ & 0.000 \\
\hline Adequate & $12(3.6)$ & $15(16.7)$ & 1 & & \\
\hline
\end{tabular}


Table 2. Multiple Logistic Regression analysis of variables affecting orthorexia nervosa

\begin{tabular}{lccc}
\multicolumn{1}{c}{ Variables } & Adjusted OR & 95\%CL & p-value \\
\hline Limited health literacy & 4.85 & $2.15-10.94$ & 0.000 \\
Instagram use & 1.69 & $1.04-2.75$ & 0.033 \\
Male & 0.51 & $0.29-0.91$ & 0.041 \\
\hline
\end{tabular}

females $(p<0.05)$. There were no significant associations between orthorexia nervosa and age groups, institution, chronic health problem, health perception, weight satisfaction, BMI $(p>0.05)$. More than half of the study group stated that they used Instagram and orthorexia nervosa was found to be significantly more common among Instagram users $(\mathrm{p}<0.05)$. Overall, the limited health literacy rate was $93.6 \%$ and the sufficient health literacy rate was $6.4 \%$. The mean score was $19.8(\mathrm{SD}=8.9)$ for the TSOY-32 scale. Limited health literacy was significantly more common among orthorexics $(\mathrm{p}<0.001)$.

Multiple binary logistic regression analysis of variables affecting $\mathrm{ON}$ is given in Table 2. ON was $4.85(\mathrm{aOR}=4.85 ; 95 \%$ C.I. $=2.15-10.94$; $\mathrm{p}=0.000$ ) times higher in those with limited health literacy, $1.69(\mathrm{aOR}=1.69 ; 95 \%$ C.I. $=1.04-2.75$; $\mathrm{p}=0.033$ ) times higher among Instagram users and $0.51(\mathrm{aOR}=0.51 ; 95 \%$ C.I. $=0.29-0.91$; $\mathrm{p}=0.041)$ times lower among males.

\section{DISCUSSION}

Although it does not appear in the Diagnostic and Statistical Manual of Mental Disorders (DSM), ON has created a research area. The diagnostic criteria recommended for ON include focus on healthy eating, food anxiety and obsession with dietary restrictions, and that these behaviors cause clinical disorders. ${ }^{(6,40)}$ Despite the fact that orthorexic individuals strive for goodness, such behavior often leads to significant negative effects on their quality of life. In extreme cases, orthorexic individuals prefer to be hungry instead of eating the "wrong" food. ${ }^{(41,42)}$

Beliefs in maintaining optimal health, the desire to stay healthy and fit and the necessity to manage non-communicable diseases make individuals more sensitive to nutrition. The present study fills a gap in the literature by exploring health literacy in orthorexics and provides an exciting opportunity to advance our knowledge of orthorexia nervosa.

In this study, four of every five teachers were determined to be orthorexics. It has been stated that the prevalence of orthorexia nervosa varies according to the communities. A total of $6.9 \%$ of the general population in Germany ${ }^{(9)}$ and $10.9 \%$ of young adults in Italy ${ }^{(43)}$ are orthorexic. It was reported that the prevalence in America is less than 1\%. ${ }^{(15)}$ In Hungarian and Lebanese studies, the prevalence of orthorexia has been shown to be $74.2 \%$ and $74.5 \%$, respectively. ${ }^{(10,44)}$ On the other hand, in studies conducted in our country, the prevalence of orthorexia was observed to be spread over a wide spectrum $(12.0-75.8 \%) .{ }^{(12,36,45)}$. The use of different instruments and cut-off points depending on cultural or religious backgrounds may be explain these differences.

However, the results obtained from the present study were higher than those from the other studies conducted abroad and was in line with the Hungarian and Lebanese studies. In our study such a higher prevalence was anticipated as being due to the educator group and suggests poor knowledge of nutrition among teachers.

In the present study, it was determined that almost all of the teachers had limited health literacy. In Sri Lanka ${ }^{(46)} 32.5 \%$ of teachers and in Turkey ${ }^{(47)} 73.8 \%$ of teachers were shown to have an insufficient / problematic health literacy level. It has been reported that health literacy is moderate in Iranian teachers. ${ }^{(48)}$ Contrary to expectations, the present study exhibits an unignorable level of low health literacy among teachers. Insufficient health competence of teachers was a thoughtful result. One of the 
issues that emerges from this finding is updating teachers' knowledge about health protection, development and treatment of diseases. It suggests that school health literacy programs are urgently needed.

However, in our study nearly all of the orthorexics had a limited level of health literacy and it has been determined that the strongest risk factor in orthorexia nervosa was limited health literacy. As a matter of fact, a Turkish study conducted in university students revealed that the level of health literacy in orthorexics is lower. ${ }^{(45)}$ It can be said that normalization of nutritional behaviors in orthorexic individuals is possible by a sufficient level of health literacy. Health literacy can be considered as an important aspect of orthorexia and adequate health literacy may be protective against orthorexia nervosa.

Gender differences in the occurrence of orthorexia nervosa have not been clearly demonstrated. As a matter of fact, in both national and international studies, there was evidence that the tendency to orthorexia differs between genders ${ }^{(49,50)}$ On the other hand, a few studies have reported that orthorexic trend did not differ in terms of gender ${ }^{(39,51)}$ In the present study, females had more orthorexics and higher risk of ON than males. This result may be explained by the behaviors to be expected in women with nutrition-sensitive approaches due to their specific life periods such as adolescence, reproductive age, pregnancy, lactation and menopause.

Instagram and social media use are more broadly related to mental health problems. Social media use in young adults has been associated with high levels of depression ${ }^{(23)}$ as well as eating disorders. ${ }^{(24)}$ In the present study, Instagram use was another risk factor for orthorexia. Indeed, a study conducted in the United Kingdom reported that the use of Instagram was associated with increased symptoms of orthorexia nervosa. ${ }^{(52)}$ Social media and ON are interconnected, especially in the field of health promotion. ${ }^{(53)}$

The present study was limited to urban primary and secondary area teachers. Other limitations of the current study include the following: (i) the use of the ORTO-15 tool due to its limited ability to accurately define orthorexia; (ii) the use of the TSOY-32 tool due to lack of a global health literacy scale. Orthorexia is a growing public health concern worldwide. Despite its poor outcomes, there remains a paucity of evidence on orthorexia and limited health literacy. Overall, these findings provide an initial indication of the role that limited health literacy may play in the onset and progression of orthorexia. Clinical screening of orthorexia nervosa should be planned for teachers in the pre- and post-graduation stage. School health literacy and social media literacy programs can open a new window into normalization of nutrition behaviors. Future studies on the current topic are therefore recommended.

\section{CONCLUSIONS}

The current findings suggest that $\mathrm{ON}$ is framed by limited health literacy among urban primary and secondary schoolteachers. School health literacy programs can open a new window into revealing orthorexic tendencies among teachers.

\section{CONFLICT OF INTEREST}

Competing interests: No relevant disclosures.

\section{CONTRIBUTORS}

GY contributed to the study conception, design, and data acquisition; SB analyzed the data; GY and SB interpreted the data and wrote the manuscript; GY was involved in critically revising the manuscript. All authors have read and agreed to the published version of the manuscript.

\section{REFERENCES}

1. World Health Organization. Noncommunicable diseases country profiles 2018 . Geneva: World Health Organization;2018. 
2. Hawkes C. Promoting healthy diets through nutrition education and changes in the food environment: an international review of actions and their effectiveness. Rome: Nutrition Division Food and Agriculture Organization of the United Nations;2013.

3. World Health Organization. Guideline 2012: sodium intake for adults and children. Geneva: World Health Organization, 2012 (Reprinted, 2014).

4. World Health Organization. Global action plan for the prevention and control of noncommunicable diseases 2013-2020. Geneva: World Health Organization;2013.

5. Chaki B, Pal S, Bandyopadhyay A. Exploring scientific legitimacy of orthorexia nervosa: a newly emerging eating disorder. J Hum Sport Exerc 2013; 8:1045-53. doi:10.4100/jhse.2013.84.14.

6. American Psychiatric Associaton. Diagnostic and statistical manual of mental disorders DSM-5. Arlington, VA, USA: American Psychiatric Publishing; 2013.

7. Plichta M, Jezewska-Zychowicz M, Gębski J. Orthorexic tendency in Polish students: exploring association with dietary patterns, body satisfaction and weight. Nutrients 2019;11:100. doi: 10.3390/nu1 1010100.

8. Koven NS, Abry AW. The clinical basis of orthorexia nervosa: emerging perspectives. Neuropsychiatr Dis Treat 2015;11:385-94. doi: 10.2147/NDT. S61665.

9. Luck-Sikorski C, Jung F, Schlosser K, Riedel-Heller SG. Is orthorexic behavior common in the general public? A large representative study in Germany. Eat Weight Disord 2019;24:267-73. doi: 10.1007/ s40519-018-0502-5.

10. Farchakh Y, Hallit S, Soufia M. Association between orthorexia nervosa, eating attitudes and anxiety among medical students in Lebanese universities: results of a cross-sectional study. Eat Weight Disord 2019;24:683-91. doi: 10.1007/ s40519-019-00724-6.

11. Ozkan A, Ulkucu A, Kanter T, Tapan M, Turgutlugil B, Çaylan A. Evaluating orthorexia tendency among Trakya University medical school students. Turkish Med Student J 2015;2:1 4.

12. Arslantap H, Adana F, Öðüt S, Ayakdap D, Korkmaz A. Relationship between eating behaviors of nursing students and orthorexia nervosa (obsession with healthy eating): a crosssectional study. Journal of Psychiatric Nursing 2017;8:137-44. doi: 10.14744/phd.2016.36854.

13. Hyrnik J , Janas-Kozik M, Stochel M, Jelonek I, Siwiec A, Rybakowski JF. The assessment of orthorexia nervosa among 1899 Polish adolescents using the ORTO-15 questionnaire. Int J Psychiatry Clin Pract 2016;20:199-203. doi: 10.1080/13651501.2016.1197271.

14. Missbach B, Dunn TM, König JS. We need new tools to assess orthorexia nervosa : a commentary on "Prevalence of Orthorexia Nervosa among College Students Based on Bratman's Test and Associated Tendencies". Appetite 2017;108:5214. doi: 10.1016/j.appet.2016.07.010.

15. Dunn TM, Gibbs J, Whitney N, Starosta A. Prevalence of orthorexia nervosa is less than $1 \%$ : data from a US sample. Eat Weight Disord 2017;22: 185-92. doi: 10.1007/s40519-016-0258-8.

16. Costa CB, Hardan-Khalil K, Gibbs K. Orthorexia nervosa: a review of the literature. Issues Ment Health Nurs 2017;38:980-8. doi:10.1080/ 01612840.2017.1371816.

17. Clifford T, Blyth C. A pilot study comparing the prevalence of orthorexia nervosa in regular students and those in University sports teams. Eat Weight Disord 2019;24:473-80. doi: 10.1007/ s40519-018-0584-0.

18. Segura-García C, Papaianni MC, Caglioti F, et al. Orthorexia nervosa: a frequent eating disordered behavior in athletes. Eat Weight Disord 2012;17: e226-33. doi:10.3275/8272.

19. Stochel M, Janas-Kozik M, Zejda J, Hyrnik J, Jelonek I, Siwiec A. Validation of ORTO-15 questionnaire in the group of urban youth aged 15-21. Psychiatr Pol 2015;49:119-34. doi:10.12740/ $\mathrm{PP} / 25962$.

20. Ramacciotti CE, Perrone P, Coli E, et al. Orthorexia nervosa in the general population: a preliminary screening using a self-administered questionnaire (ORTO-15). Eat Weight Disord 2011;16:e12730.doi:10.1007/BF03325318.

21. Holland G, Tiggemann M. A systematic review of the impact of the use of social networking sites on body image and disordered eating outcomes. Body Image 2016;17:100-10. doi: 10.1016/j.bodyim. 2016.02.008.

22. Qutteina Y, Nasrallah C, Kimmel L, Khaled SM. Relationship between social media use and disordered eating behavior among female university students in Qatar. J Health Soc Sci 2019; 4:59-72. doi: 10.19204/2019/rltn7.

23. Lin LY, Sidani JE, Shensa A, et al. Association between social media use and depression among US young adults. Depress Anxiety 2016;33:32331. doi: 10.1002/da.22466.

24. Carrotte ER, Vella AM, Lim MS. Predictors of "liking" three types of health and fitness-related content on social media: a cross-sectional study. 
J Med Internet Res 2015;17:e205. doi: 10.2196/ jmir.4803.

25. Speirs KE, Messina LA, Munger AL, Grutzmacher SK. Health literacy and nutrition behaviors among low-income adults. J Health Care Poor Underserved 2012;23:1082-91. doi: 10.1353/ hpu.2012.0113.

26. Zoellner J, You W, Connell C, et al. Health literacy is associated with healthy eating index scores and sugar-sweetened beverage intake: findings from the rural Lower Mississippi Delta. J Am Diet Assoc 2011;111:1012-20. doi:10.1016/ j.jada. 2011.04.010.

27. Sørensen K, Van den Broucke S, Fullam J, et al. Health literacy and public health: a systematic review and integration of definitions and models. BMC Public Health 2012;12:80 doi:10.1186/14712458-12-80.

28. Yang SJ, Chee YK. Development and psychometric testing of the Health Literacy Index for Female Marriage Immigrants (HLI-FMI) in Korea. Women Health 2017;57:1007-30. doi: 10.1080/03630242.2016.1222328.

29. van der Vaart R, Drossaert C J. Development of the digital health literacy instrument: measuring a broad spectrum of Health 1.0 and Health 2.0 skills. Med Internet Res 2017;19:e27. doi:10.2196/ jmir.6709.

30. Peralta L, Rowling L, Samdal O, Hipkins R, Dudley D. Conceptualising a new approach to adolescent health literacy. Health Educ J 2017;76:787-801. doi: 10.1177/0017896917714812.

31. Mounsey A, Sexton B. Health literacy tools in the outpatient setting. Am Fam Physician 2017;96: 252.

32. Mafutha NG, Mogotlane S, De Swardt H. Development of a hypertension health literacy assessment tool for use in primary healthcare clinics in South Africa, Gauteng. Afr J Prim Health Care Fam Med 2017;98. doi: 10.4102/phcfm.v9i1. 1305.

33. Sørensen K, Pelikan JM, Röthlin F, et al. Health literacy in Europe: comparative results of the European health literacy survey (HLS-EU). Eur J Public Health 2015;25:1053-8. doi:10.1093/eurpub/ ckv043.

34. Okyay P, Abacýgil F. Türkiye Saðlýk Okuryazarlýðý Ölçekleri Güvenilirlik ve Geçerlilik Çalýpmasý. 1. Baský. Ankara: Anýl Matbaa; 2016. pp. 43-60.

35. Durusu-Tanrýöver M, Yýldýrým HH, DemirayReady FN, Çakýr B, Akalýn HE. Turkey health literacy research. Ankara: Saðlýk-SenYayýnlarý; 2014.
36. Ermumcu $\mathrm{M}^{\mathrm{a}} \mathrm{K}$, Nilüfer AT. Healthy eating concern in health professionals: orthorexia nervosa $(\mathrm{ON})$. J Gazi Health Sci 2016;1:59-71.

37. Reynolds R, McMahon S. Views of health professionals on the clinical recognition of orthorexia nervosa: a pilot study. Eat Weight Disord 2020;25:1117-1124. doi:10.1007/s40519019-00701-z.

38. Kiss-Leizer M, Rigó A. People behind unhealthy obsession to healthy food: the personality profile of tendency to orthorexia nervosa. Eat Weight Disord 2019;24:29-35. doi:10.1007/s40519-0180527-9.

39. Asil E, Sürücüoðlu MS. Orthorexia nervosa in Turkish dietitians. Ecol Food Nutr 2015;54:30313. doi: 10.1080/03670244.2014.987920.

40. Dunn TM, Bratman S. On orthorexia nervosa: A review of the literature and proposed diagnostic criteria. Eat Behav 2016;21:11-7. doi: 10.1016/ j.eatbeh.2015.12.006.

41. Donini LM, Marsili D, Graziani MP, Imbriale M, Cannella C. Orthorexia nervosa: a preliminary study with a proposal for diagnosis and an attempt to measure the dimension of the phenomenon. Eat Weight Disord 2004;9:151-7. doi: 10.1007/ bf03325060.

42. Brytek-Matera A, Rogoza R, Gramaglia C, Zeppegno P. Predictors of orthorexic behaviours in patients with eating disorders: a preliminary study. BMC Psychiatry 2015; 15:252. doi: 10.1186/ s12888-015-0628-1.

43. Cinosi E, Matarazzo I, Marini S, et al. Prevalence of orthorexia nervosa in a population of young Italian adults. European Psychiatry 2015;30:1330. doi.org/10.1016/S0924-9338(15)31038-5.

44. Varga M, Thege BK, Dukay-Szabó S, Túry F, Van Furth EF. When eating healthy is not healthy: orthorexia nervosa and its measurement with the ORTO-15 in Hungary. BMC Psychiatry 2014;14:59. doi: 10.1186/1471-244X-14-59.

45. Pehlivan E, Mete B, Fýrýncý B, Doðan E. Prevalence of orthorexia nervosa and its relations with health literacy in university students. ESTUDAM Public Health J 2019;4:166-75. doi: 10.35232/estudamhsd.500538.

46. Denuwara HMBH, Gunawardena NS. Level of health literacy and factors associated with it among school teachers in an education zone in Colombo, Sri Lanka. BMC Public Health 2017; 17 : 631. doi: 10.1186/s12889-017-4543-x

47. Yilmazel G, Çetinkaya F. Health literacy among schoolteachers in Çorum, Turkey. East Mediterr Health J 2015;21:598-605. doi:10.26719/2015.21. 8.598 . 
48. Asadian A, Sotoudeh A, Zarei Venovel M, Moosai R. Investigating health literacy of teachers in Asaluyeh. Soc Behav Res Health 2018;2:234-28. doi: 10.18502/sbrh.v2i2.284.

49. Parra-Fernández ML, Rodríguez-Cano T, OnievaZafra MD, et al. Prevalence of orthorexia nervosa in university students and its relationship with psychopathological aspects of eating behaviour disorders. BMC Psychiatry 2018;18:364. doi: 10.1186/s12888-018-1943-0.

50. Yeșil E, Turhan B, Tatan D, Şarahman C, Saka M. The effect of gender to orthorexia nervosa tendency in adults. J Ankara Health Sci 2018;7:19.
51. Brytek-Matera A, Donini LM, Krupa M, Poggiogalle E, Hay P. Orthorexia nervosa and selfattitudinal aspects of body image in female and male university students. J Eat Disord 2016;16:16. doi:10.1186/s40337-015-0038-2.

52. Turner PG, Lefevre CE. Instagram use is linked to increased symptoms of orthorexia nervosa. Eat Weight Disord 2017;22:277-84. doi: 10.1007/ s40519-017-0364-2.

53. Robert M, Callahan L, O'Leary C. Social media: A path to health literacy. Stud Health Technol Inform 2017;37:177-87. doi:10.3233/ISU-170836. 